EDITORIAL

\title{
El desafío de transformar la formación docente y asegurar el cambio del modelo educacional*
}

\author{
Alberto Galaz, ${ }^{a}$ Rodrigo Fuentealba, ${ }^{b}$ José Cornejo, ${ }^{c}$ Alfonso Padilla ${ }^{d}$
}

\section{COORDINADORES}

\begin{abstract}
aUniversidad Austral de Chile, Correo electrónico: Alberto.galaz@uach.cl bUniversidad San Sebastián, Correo electrónico: rodrigo.fuentealba@uss.cl 'Pontificia Universidad Católica de Chile, Correo electrónico: jcorneja@puc.cl dPontificia Universidad Católica de Chile, Correo electrónico: apadilla@puc.cl
\end{abstract}

Hemos asistido a variados ciclos de reforma y contrarreforma educativa. Cada nuevo gobierno realiza ingentes esfuerzos para promover y convencer a la ciudadanía de que sus respectivos programas y propuestas le cambiarán el rostro a la educación. Pero tras aparentes diferencias, muchas veces más bien de orden comunicacional que de fondo, lo cierto es que en los últimos 20 años el cambio educativo ha transcurrido inevitablemente por un permanente déjà $v u$ político.

A nuestro juicio, esto es el resultado de la hegemonía de una determinada racionalidad y del despliegue de un conjunto de principios científico-técnicos bajo lo cuáles, estratégicamente, se ha fundado el modelo educativo actual. Un modelo que se asume neutral y que se atavía de un incontestable velo de naturalización. En esta línea, Foucault (2009) señalaba que en sociedades como la nuestra la verdad acerca de los diferentes objetos y sujetos encuentra en estos principios un gran eje de re-producción. Por su parte Fardella (2012) advierte que el discurso científico-técnico, al generar una distancia entre el narrador y lo dicho, adopta una posición de falsa objetividad, desprovista ideológicamente. De esa forma el enunciado pareciera ser una descripción científica de un hecho externo.

No resulta extraño entonces que, desde las políticas de masificación a las actuales iniciativas de mejoramiento y evaluación de la eficiencia del desempeño, las señales de cambio en educación hayan sido débiles y en oportunidades no menos contradictorias. Sustentadas en dicha racionalidad y principios, las medidas elaboradas han venido insistiendo en la implementación de dispositivos de acreditación, estandarización, evaluación, premios y castigos que apuntan más bien a la simplificación de complejas realidades y al control de las acciones, configurando un escenario que, de forma contradictoria, no cumple en forma alguna con las expectativas que el propio sistema social tiene de su sistema de educación.

Al interior de este escenario, profesores y profesoras han gravitado bajo modelos e imágenes exclusivas y excluyentes (Galaz, 2014), porque en tanto son conminados a asumir la responsabilidad de los resultados de la educación, demandados a implementar un curriculum escolar complejo y obligados a someterse a desgastantes procesos evaluativos;

Este número especial se realiza en el contexto del proyecto FONDECYT Nº 1110177. 
paradojalmente éstos no cuentan aún con una carrera profesional que, junto con brindarles estabilidad, les asegure condiciones dignas de trabajo y reales oportunidades de desarrollo. Aun más, en proyectos actualmente en discusión incluso se atenta contra el principio de exclusividad del campo laboral (eje clave de distinción de toda profesión) al establecerse la posibilidad de que profesionales de otras áreas puedan ser habilitados para ejercer docencia en escuelas y liceos.

A pesar de que la mayoría de las iniciativas dirigidas hacia el cuerpo docente señala fundamentarse en principios socio-constructivistas, la lógica de su diseño e implementación atenta contra toda posibilidad de posicionarse activa y creativamente. $\mathrm{Y}$ es que, salvo experiencias específicas y acotadas de desarrollo profesional, la estrategia adoptada ha sido fundamentalmente aquella de la fragmentación identitaria o del permanente cuestionamiento de la identidad profesional. De forma indirecta cuando atendemos al sentimiento de pérdida de estatus o, de forma directa, cuando se ha buscado reformular los contenidos de su formación inicial para adecuarlos a los objetivos políticos educativos.

Las consecuencias más evidentes de este proceso han sido la reducción de la autonomía y el desarrollo de un creciente sentimiento de desprofesionalización. No debiera sorprender, por tanto, la suspicacia y la ausencia de adhesión al cambio. Profesoras y profesores no han podido verificar o comprobar la veracidad del mediático discurso político que les ha asignado un rol clave en el mejoramiento de la calidad de la educación.

La pregunta resultante es consabida ¿por qué es tan difícil lograr cambios efectivos en las prácticas de los profesores?

La respuesta no se halla en el argumento, sino en la disposición. En su implementación, la mayoría de las iniciativas oficiales subestiman las respuestas construidas por profesores y profesoras. En este sentido, puede aludirse a un choque de lógicas epistémicas divergentes. Más específicamente entre una de carácter científica-técnica que fundamenta el diseño de políticas para la sustitución y otra de lo cotidiano, que a diferencia de la primera, se fundamenta bajo criterios de cooperación, legitimidad y factibilidad. Es más, el supuesto subyacente en la segunda posición es que sólo quien vivencia los propios rigores de la construcción cotidiana de su desempeño sabe lo fundamental de sus orientaciones y proyecciones para el desarrollo profesional.

No obstante, si bien la estructura del modelo educativo se ha mantenido básicamente inalterable, no todo ha sido precisamente calma y estabilidad. Su impermeabilidad a lógicas divergentes deja en evidencia su principal debilidad, aquella del establecimiento de una distancia insalvable entre el mundo político y el social, con la consiguiente desarticulación de propósitos entre autoridades-expertos y las inter-subjetividades de los actores educativos. Una fractura que configura, a nuestro juicio, un mapa sin coordenadas precisas para la identificación y orientación subjetiva de los actores en el sistema social, y que tarde o temprano, devendrá en una crisis de representación.

Urge, por lo tanto, recuperar el sentido noble de la política, así también su compleja y caótica naturaleza, aquella de acoger las demandas, los malestares, las ansiedades y las dudas de la gente a fin de incorporar sus vivencias en el discurso. De esta forma, dando cabida a la subjetividad, dirá Lechner (2002), la política da al ciudadano la oportunidad de reconocer (se) en su experiencia como parte de la vida en sociedad.

En este contexto, y a fin de abordar de manera crítica la escasa representatividad y adhesión que sufren las políticas públicas en general y las educativas en particular, la actual definición de iniciativas para la formación y el desarrollo profesional de profesoras 
y profesores debe ser concebida como una oportunidad estratégica para revalorizar su dimensión subjetiva e intersubjetiva. Cabe preguntarse entonces si las políticas dirigidas a la educación y al profesor seguirán el consabido camino de la desmaterialización social, si optarán fundamentalmente por la prescripción y si continuarán colocando el acento en la estandarización de la práctica.

En la actual coyuntura histórico-política, el llamado del presente número especial de la Revista Estudios Pedagógicos es tomar distancia de aquellas posturas tecnocráticas que pretenden hacernos creer que las transformaciones en educación deben operar fundamentalmente a nivel de inyección de recursos, competencias y el diseño de dispositivos de control o supervisión.

Nuestro convencimiento es que los problemas y conflictos sociales del país y las expectativas que se tienen del sistema educativo en general, y de profesores y profesoras en particular, requieren de participación, compromisos y transformaciones radicales. Solo así se podrá avanzar hacia una nueva etapa, una etapa donde la formación de los profesionales de la educación se conciba como un desafío de política educativa con miras a repensar el país que queremos ser y habitar. Pero dicha transformación será una tarea que exigirá el desarrollo de miradas complejas sobre el sistema y la participación de todos los actores, en todos los sectores sociales. La investigación, el análisis crítico y el diálogo ampliado han de ser las herramientas e instancias donde se discutan las certezas y resistencias epistemológicas del modelo. El desafío, por lo tanto, no es menor.

En esta dirección, y con la finalidad de definir las bases de una efectiva política y de un sistema de desarrollo profesional que reconozca efectivamente el ser y hacer de profesores y profesoras, rescatamos y valoramos los antiguos y actuales esfuerzos, así también las experiencias alternativas y exitosas que se han desarrollado y que hoy desarrollan diversos actores en el sistema educativo.

Las investigaciones y revisiones aquí reunidas evidencian parte significativa de estos esfuerzos. Ellas pueden ser consideradas de alta relevancia, no solo porque toman distancia metodológica y de propósitos respecto de aquellos estudios que orbitan en el campo de gravedad del actual sistema, sino además porque sus análisis, realizados desde coordenadas subjetivas, colectivas, políticas, identitarias e institucionales, han permanecido como dimensiones no abordadas o no visualizadas por autoridades y policy makers.

Así y a través de 18 artículos, nueve investigaciones y nueve revisiones, provenientes de cinco países (Brasil, Canadá, España, Francia y Chile) se configura un escenario donde desde distintos ángulos se aborda el tema del cambio y de las condiciones necesarias para llevarlo a cabo.

Desde los distintos contextos, formación inicial, los formadores de formadores y el ejercicio profesional se abordan diversos tópicos, tanto desde la mirada política como de dispositivos formativos los que en su conjunto invitan a re-mirar de manera crítica los actuales planteamientos que dominan el escenario educativo.

Tal como lo hemos expresado en publicaciones como Estrategias reflexivas en la formación de profesores y formadores de profesores (2011), nuestra opción ha sido asumir la importancia radical de tal diversidad y de concebir estos aportes como apuestas de develamiento de principios ocultos, a partir de los cuales es posible evaluar y discutir sobre la naturaleza política de las estrategias de formación.

Este número especial ha sido posible gracias al desafío de transformar la formación docente que asumen las y los autores aquí reunidos, como así también por el apoyo 
significativo que ha otorgado la Comisión Nacional de Ciencia y Tecnología, particularmente a través de su Fondo Nacional de Desarrollo Científico y Tecnológico (Fondecyt).

Mención especial debe recibir la Organización de Estados Iberoamericanos (OEI) quien desde un comienzo creyó en este proyecto y no dudó en otorgar su ayuda para materializarlo.

Finalmente nuestro agradecimiento es para el colega Roberto Casanova de la Universidad Austral de Chile quien no solo realizó el riguroso trabajo de revisión de estilo de los artículos, sino que también compartió muchas de las ideas expresadas.

\section{REFERENCIAS BIBLIOGRÁFICAS}

Fardella, C. (2012). Verdades sobre la docencia, efectos y consecuencias subjetivas de la evaluación docente en Chile. Revista de Psicología, vol.21, n.1, 209-227.

Foucault, M. (2009). Historia de la sexualidad. La Voluntad del saber. Madrid: Siglo XXI.

Galaz, A., Fuentealba, R., Cornejo, J. y Padilla, A (2011). Estrategias reflexivas en la formación de profesores y formadores de profesores. ¿Qué desafíos se proyectan desde la formación basada en competencias? Valdivia: Ediciones Universidad Austral de Chile.

Galaz, A., Vega, J., Lizama, P., Schick, C., Lillo, R. y Cárdenas, P. (2014). El profesor y su identidad profesional: un espacio de lucha por el reconocimiento y la autonomía. En Moreno, A y Arancibia, M. Educación y Transformación social. Construyendo ciudadanía crítica (pp. 114-131). Valparaíso: Ediciones PUCV.

Lechner, N. (2002). Las sombras del Mañana. La dimensión subjetiva de la política. Santiago: LOM Editores. 